\title{
Editorial
}

\section{Nuevos tiempos, nuevos aires..., alcanzando la excelencia}

Estamos de celebración. En primer lugar porque la revista Cuadernos de Psicología del Deporte (CPD) cumple 12 años de actividad ininterrumpida, periodo en el que han visto la luz un total de 13 volúmenes y 23 números, con la publicación de un total de 300 artículos, 48 recensiones, 1 monográfico y 5 suplementos. En segundo lugar porque CPD ha logrado, desde el trabajo, el rigor y la humildad, ubicarse con gran visibilidad y respetabilidad en el campo de las publicaciones de las Ciencias del Deporte, siendo en la actualidad una de sus referencias. Y en tercer lugar porque los esfuerzos, ilusiones y expectativas del Grupo de Investigación de Psicología del Deporte de la Universidad de Murcia y sus colaboradores se han visto refrendados con la inclusión muy reciente de CPD en las bases de datos de ISI-Thompson Reuters, lo que nos llena de satisfacción y nos presenta nuevos retos que acometer. Estos tres puntos de celebración no hubieran sido posibles sin el trabajo y colaboración de autores, revisores y lectores a los que desde aquí queremos mostrar nuestro más sentido agradecimiento.

Desde su creación en el año 2001, y con la ayuda inestimable de la Dirección General de Deportes de la Comunidad Autónoma de la Región de Murcia (CARM) durante toda su andadura, se han vivido tres grandes etapas. La primera de ellas, comprende desde su nacimiento en el año 2001, hasta que se produce la primera restructuración en el Comité de Dirección de la revista, en el año 2006. Durante esa primera época el director y fundador de la revista fue el profesor Dr. D. Enrique Garcés de los Fayos Ruiz, que junto al resto de miembros del Comité de Redacción y del Comité Científico, consiguieron no solo poner en marcha la revista, sino lograr que CPD fuese un referente en el ámbito de la investigación aplicada. Debido al doble perfil del director, investigador y profesional aplicado, en la primera etapa se observa una preocupación por ambos temas, apreciándose una línea editorial rigurosamente científica, pero preocupada por la aplicación del conocimiento científico generado al ámbito aplicado.

Tras el extraordinario trabajo del profesor Garcés de los Fayos, en el año 2006 se produce la primera gran restructuración del Comité Científico, de manera que CPD pasa a ser dirigida por el profesor Dr. D. Francisco J. Ortín Montero, el cual sigue manteniendo esa doble perspectiva de investigación y aplicación. En esta época los grandes logros fueron fundamentalmente dos: 1) la apertura de CPD al resto de áreas de las ciencias del deporte; y 2) la preocupación por la excelencia en la investigación, debido a lo cual la revista fue incluida en las grandes bases de datos de revistas científicas, destacando Scopus, Psycinfo, Sportdiscus, Redalyc, Scielo y Ebscohost. Merece indicar que a pesar de ser una revista específica, de Psicología del Deporte, ha logrado un aumento año tras años en índices de Impacto como el de Revistas Españolas de Ciencias Sociales IN-RECS, o el Google Scholar, alcanzando en su última actualización los puestos más altos. Por otro lado, en esta etapa se ha seguido en la línea de apostar claramente hacia el doble perfil de investigación y de aplicación de la revista, con gran sensibilidad en la consolidación de los lazos con Latinoamérica.

Y este año 2014 recién iniciado comienza con una nueva andadura en la historia de CPD. En concreto, y por diferentes circunstancias, entre otras por la alta posición de la revista, el elevado número de artículos que llegan y los nuevos retos a afrontar, consideramos imprescindible configurar un equipo de redacción más amplio, con mayor adecuación a las diferentes necesidades a las que debemos responder. Por ello, ya se ha diseńado un nuevo equipo para el Comité Editorial: el profesor Dr. D. Aurelio Olmedilla Zafra, Editor Jefe, el profesor Dr. D. Juan González Hernández, Director, y la profesora Dra. Da Gema Torres Luque, Directora Adjunta. Como Editores Adjuntos los profesores Dr. D. Enrique J. Garcés de los Fayos Ruiz, Dr. D. Francisco J. Ortín Montero, Dr. D. Enrique Ortega Toro y D. Pedro Jara Vera. Además se ha creado una estructura tanto de Editores Asociados como Comité Científico de Psicología del Deporte por un lado y de Ciencias del Deporte por otro, así como otras secciones que esperamos cerrar a lo largo del primer trimestre del 2014.

En esta nueva etapa se vislumbran nuevos retos, difíciles pero muy gratificantes y estimuladores, que deseamos conseguir cumpliendo aquellos objetivos que consideramos fundamentales:

1. Aumentar la apertura a las Ciencias del Deporte, creando una sección propia.

2. Aumentar la visibilidad internacional de CPD, para lo que, entre otras estrategias de actuación, se pretende incluir en la nueva estructura de la revista a autores de reconocido prestigio de diferentes universidades (latinoamericanas, norteamericanas, europeas, etc.).

3. Aumentar la cercanía de la investigación al campo apli- 
cado. En este sentido, en las nuevas normas para los autores se indica la necesidad de incluir una sección fija de "Aplicaciones prácticas" en los manuscritos enviados; sección en la que el investigador deberá señalar la aportación de su trabajo al ámbito práctico, presentando incluso ejemplos concretos de cómo poder aplicar el conocimiento que genera al ámbito profesional del entrenador, del psicólogo, del recuperador funcional, del preparador físico, del fisioterapeuta, del profesor, etc.

4. Consolidar CPD en las nuevas Bases de Datos internacionales, y por tanto ser vehículo de difusión de la investigación aplicada atendiendo paulatinamente a otros ámbitos culturales y geográficos, como el europeo, el anglosajón y otros.

Son muchos los compañeros que CPD ha tenido a lo largo de su trayectoria, si bien, es de justicia reconocer el apoyo incondicional que $\mathrm{CPD}$ ha tenido principalmente de dos instituciones, como la Dirección General de Deportes de la CARM y la Facultad de Psicología de la Universidad de Murcia (con Jesús Gómez Amor como Decano impulsor de CPD en su creación, y Juan José López García, actual Decano, que siempre ha impulsado la adhesión a este proyecto); además, el constante apoyo de la Sociedad Iberoamericana de Psicología del Deporte (SIPD) y de la Federación Española de Psicología del Deporte (FEPD), y del cada vez más creciente de la Sociedad Murciana de Psicología de la Actividad Física y del Deporte (SMPAFD). Desde el ámbito profesional, y desde su reciente creación la División de Psicología de la Actividad Física y el Deporte del Colegio Oficial de Psicólogos siempre ha mostrado su apoyo a CPD, manifestado incondicionalmente por su coordinador el doctor Enrique Cantón Chirivella, al que nos une una larga trayectoria común. Muchas gracias.

De obligado y querido cumplimiento es terminar esta Editorial agradeciendo a la Revista de Psicología del Deporte (RPD) y a la Revista Iberoamericana de Psicología del Ejercicio (RIPED) simplemente el estar ahí. Los que ya llevamos unos años en esta aventura no podemos agradecer lo suficiente lo que significó RPD en nuestro desarrollo investigador y profesional, cuando a partir de 1992 pudimos consumir artículos de psicología del deporte con verdadero entusiasmo. Desde entonces tanto su director, el profesor Jaume Cruz i Feliú, como su editor jefe, el profesor Alexandre García Mas, han mostrado siempre su más decidido apoyo y un sentido cariño a CPD y a las personas que han trabajado en ella. En 2006 aparece el primer número de RIPED, otra revista hermana que se ha caracterizado por estrechar lazos con los autores y lectores latinoamericanos, y su editor, el profesor Félix Guillén García, siempre ha mostrado su disponibilidad y ayuda a CPD en esta singladura que es el ámbito de las publicaciones científicas, y más en un área tan específica como la Psicología del Deporte. Muchas gracias de corazón.

En esta nueva etapa, esperamos seguir con su apoyo incondicional, y poder alcanzar los objetivos marcados. Para ello será imprescindible contar con los verdaderos protagonistas de CPD: sus autores y sus lectores.

Gracias a todos

Aurelio Olmedilla, Juan González, Gema Torres, Enrique J. Garcés de los Fayos, Francisco J. Ortín, Enrique Ortega y Pedro Jara 